\section{Closure to "Debris-Blocking Sensitivity of Piano Key Weirs under Reservoir-Type Approach Flow" by Michael Pfister, Damiano Capobianco, Blake Tullis, and Anton J. Schleiss}

DOI: 10.1061/(ASCE)HY.1943-7900.0000780

\author{
Michael Pfister ${ }^{1}$; Blake Tullis, M.ASCE ${ }^{2}$; and \\ Anton J. Schleiss ${ }^{3}$ \\ ${ }^{1}$ Research and Teaching Associate, Laboratory of Hydraulic Constructions \\ (LCH), Ecole Polytechnique Fédérale de Lausanne (EPFL), CH-1015 \\ Lausanne, Switzerland (corresponding author). E-mail: michael \\ .pfister@epfl.ch \\ ${ }^{2}$ Professor, Utah State Univ., 8200 Old Main Hill, Logan, UT 84322. \\ E-mail: blake.tullis@usu.edu \\ ${ }^{3}$ Professor, Laboratory of Hydraulic Constructions (LCH), Ecole Polytech- \\ nique Fédérale de Lausanne (EPFL), CH-1015 Lausanne, Switzerland. \\ E-mail: anton.schleiss@epfl.ch
}

The writers were pleased to read the overview of some work published so far on piano key weirs (PKWs) and labyrinth weirs as presented by the discusser. Besides the publications mentioned by the discusser, two recent workshop proceedings give a comprehensive summary on the current state of the art on PKWs and labyrinth weirs (Erpicum et al. 2011, 2013).

Regarding the discussed paper on the effect of driftwood on the discharge efficiency of PKWs (Pfister et al. 2013a), some additional insights can be added that have been gained in the meantime as a result of further model investigations and prototype observations, as well as discussions with dam operators using PKWs on their spillways.

\section{Remarks on the Sensitivity of PKWs Regarding Debris}

PKWs are probably less sensitive to the effect of driftwood on the discharge capacity than classical weir types, as for instance ogees. However, there is presently a lack of explicit observations allowing for a direct comparison. Nevertheless, the following facts support this assumption:

1. Considering a virtual approach flow channel upstream of built or planned PKWs owned by Électricité de France (EDF) (Laugier et al. 2013) with a width $W$ and a height $P+H$ under their design discharge $Q$ results in maximum channel approach flow Froude number $\mathrm{F}=Q /\left[W^{0.5}(P+H)^{1.5}\right]$ of $0.1 \leq \mathrm{F} \leq 0.3$. For reservoir conditions, these values tend to zero. The approach velocity of floating debris is thus rather small, supporting a plain and loose accumulation. Consequently, and contrary to classical weirs, no vertical stacking of debris was observed at PKWs; and

2. The plain blockage is often limited to the reach upstream of the PKW, ending close to the upstream crest of the outlet key. The PWK itself remains mostly clear, and the water can pass below the debris and enter the inlet key unhindered by the blockage. As indicated by numerical simulations (e.g., Ackers et al. 2013) and physical model tests (e.g., Machiels et al. 2011), a significant part of the spilled discharge travels into the inlet key from below, without reaching the free surface upstream of the PKW where the blockage occurs.

The maximum absolute reservoir head increase never exceeded some 0.15 to $0.20 \mathrm{~m}$ (prototype scale) in reported tests with the reservoir type approach flow. This maximum was observed for unit discharges up to almost $13 \mathrm{~m}^{2} / \mathrm{s}$ and unit debris volumes up to $9 \mathrm{~m}^{3} / \mathrm{m}$ (Pfister et al. 2013b).

Furthermore, prototype observations at the EDF Malarce Dam (France) confirmed the above assumptions. During a flood in November 2014 with a unit discharge of about $4 \mathrm{~m}^{2} / \mathrm{s}$ (near $30 \%$ of the design discharge) significant debris volumes arrived at the PKW. Most trunks passed the PKW, and few blocked at the upstream crest of the outlet key, mostly at the right part of the PKW (Fig. 1). Consequently, the PKW itself remained practically clear and unaffected, even at its right part where the debris blocked. The flow surfaces and depths in the inlet keys appeared to be similar between the right (blocked) and left (debris-free) sides of the PKW, because the inlet keys are mainly fed from lower in the water column. The hydraulic head associated to the measured discharge is slightly below $0.5 \mathrm{~m}$, and the related critical flow depth around $0.3 \mathrm{~m}$. Observations indicated that mainly trunks with diameters $D \geq 0.3 \mathrm{~m}$ initiated the blockage, being in agreement with the individual trunk tests as described by the writers.

\section{Limitations}

The application of the results presented by the writers is, among others, limited to the following conditions:

1. PKWs installed on dam crests with an upstream reservoir: The approach flow momentum of the trunks is a priori negligible. The debris-blocking process is affected if the trunks arrive faster (e.g., Schmocker and Hager 2011), as for instance when the PKW is installed on a river. Channelized PKW applications have recently been built in Vietnam (Ho Ta Khan et al. 2011);

2. Debris arriving at the crest when the PKW is already in operation: The possibility of driftwood blockage under the overhangs during reservoir filling was not considered. Debris

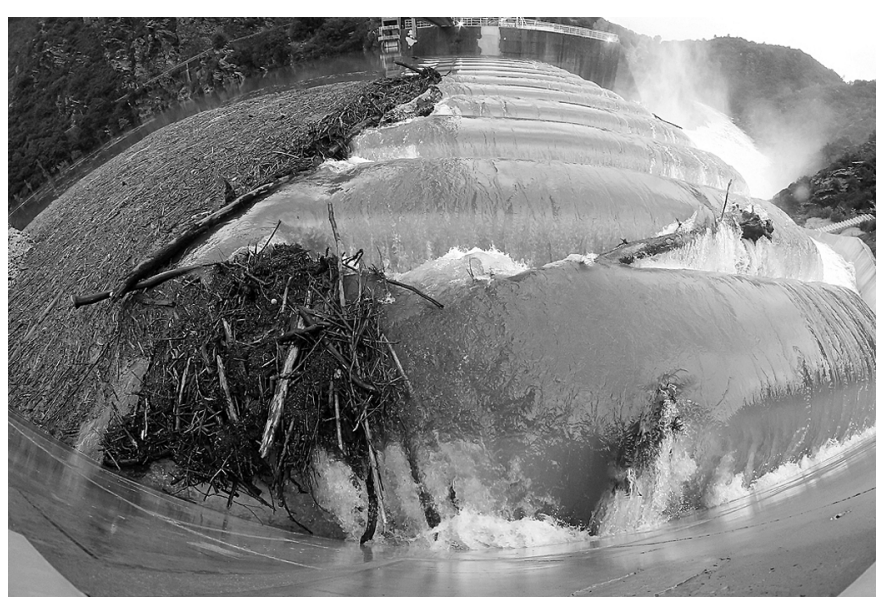

Fig. 1. Malarce Dam (F) PKW during the November 2014 flood event with debris blocking at its right part (photo: EDF France) 
accumulations could definitely arrive at the PKW before the PKW spills, mainly due to the global current in a reservoir, induced by an operating principal spillway or due to wind;

3. Steady discharge during debris arrival: Effective hydrographs during a flood event may influence the behavior of the debris at the weir; and

4. The effects of additional appurtenant structures (e.g., bridge piers, etc.) in conjunction with the PKW on debris passage were not considered.

\section{References}

Ackers, J. C., Bennett, F. C. J., Scott, T. A., and Karunaratne, G. (2013). "Raising the bellmouth spillway at Black Esk reservoir using Piano Key weirs." Labyrinth and Piano Key weirs II, CRC Press/Balkema, Leiden, Netherlands, 235-242.

Erpicum, S., Laugier, F., Boillat, J. L., Pirotton, M., Reverchon, B., and Schleiss, A. J., eds. (2011). Labyrinth and Piano Key weirs, CRC Press/Balkema, Leiden, Netherlands.
Erpicum, S., Laugier, F., Pfister, M., Pirotton, M., Cicéro, G. M., and Schleiss, A. J., eds. (2013). Labyrinth and Piano Key weirs II, CRC Press/Balkema, Leiden, Netherland.

Ho Ta Khan, M., Quat, D. S., and Thuy, D. X. (2011). "P.K. weirs under design and construction in Vietnam (2010)." Labyrinth and Piano Key weirs, CRC Press/Balkema, Leiden, Netherlands, 225-232.

Laugier, F., Vermeulen, J., and Lefebvre, V. (2013). "Overview of Piano Key weirs experience at EDF during the past few years." Labyrinth and Piano Key weirs II, CRC Press/Balkema, Leiden, Netherlands, 213-226.

Machiels, O., Erpicum, S., Dewals, B., Archambeau, P., and Pirotton, M. (2011). "Experimental observation of flow characteristics over a Piano Key weir." J. Hydraul. Res., 49(3), 359-366.

Pfister, M., Capobianco, D., Tullis, B., and Schleiss, A. J. (2013a). "Debris blocking sensitivity of Piano Key weirs under reservoir type approach flow.” J. Hydraul. Eng., 10.1061/(ASCE)HY.1943-7900.0000780, 1134-1141.

Pfister, M., Schleiss, A. J., and Tullis, B. (2013b). "Effect of driftwood on hydraulic head of Piano Key weirs." Labyrinth and Piano Key weirs II, CRC Press/Balkema, Leiden, Netherlands, 255-264.

Schmocker, L., and Hager, W. H. (2011). "Probability of drift blockage at bridge decks." J. Hydraul. Eng., 10.1061/(ASCE)HY.1943-7900 .0000319, 470-479. 